\title{
Pràctica sobre el càlcul de les propietats fonamentals del so a partir de la freqüència d'ultrasò d’ecolocalització dels ratpenats.
}

\author{
Pedro Arcas Rivas (pedro.arcas@ribotiserra.cat) IES Institut Ribot i Serra, (Sabadell) \\ José Fenollar Moncho (jfenoll2@xtec.cat) IES Institut Ribot i Serra, (Sabadell)
}

El ratpenat o quiròpter emet unes freqüències d'ultrasò en forma de crit (generalment entre $20 i 120 \mathrm{kHz}$ ). En aquesta pràctica treballarem conceptes relacionats amb les característiques d'aquest so, detectat amb el detector Bat Tune: freqüència $f$, període $T$, freqüència angular o pulsació $w$, longitud d'ona $\lambda$ i el nombre d'ona $k$.

Paraules clau: Ratpenats, ona, ultrasò, freqüència, període, freqüència angular o pulsació, longitud d'ona i el nombre d`ona.

The different species of bats emits some ultrasound frequencies in a form of ultrasound (usually between 20 and $120 \mathrm{kHz}$ ). In this practice we will work on concepts related to the characteristics of this sound, detected with the Bat Tune detector: frequency $f$, period $T$, angular frequency or pulsation $w$, length of wave $\lambda$ and the number of wave $k$.

Keywords: Bats, wave, ultrasound, frequency, period, angular frequency or pulsation, length of the wave and the number of wave.

\section{INTRODUCCIÓ}

El so és un fenomen vibratori transmès en forma d'ones (audibles o no). El so pot representar-se com un moviment ondulatori amb longitud d'ona $(\lambda$, període espacial existent entre dos polsos consecutius que posseeixen la mateixa fase); freqüència ( $f$, és el nombre de repeticions per unitat de temps d'un succés periòdic), amplitud (indica l'energia que conté el senyal) i fase (és la fracció del període transcorregut des de l'estat inicial, varia cíclicament) (Cortés-Calva, P., 2013). El ratpenat o quiròpter emet $a m b$ freqüències d'ultrasò (freqüències altes).

\section{L’ecolocalització}

L'ecolocalització (sonar) és una pràctica utilitzada basada en l'orientació a l'hora de caçar a la foscor. El ratpenat emet unes freqüències d'ultrasò (freqüències altes) en forma de crit (generalment entre 20 i $120 \mathrm{kHz}$ ) que reboten amb els objectes que hi ha al davant del mamífer i tornen: d'aquesta manera, el ratpenat els capta amb l'oïda aconseguint conèixer amb rigor el seu entorn a la perfecció. Aquesta tècnica tan exacta i precisa és utilitzada per la caça d'insectes en situacions de penombra. A nivell funcional també permet comunicar-se amb altres membres d'una mateixa espècie.

\section{Detectors d'ultrasons}

L'estudi de quiròpter es veu afectat per fet de ser animals voladors nocturns que desenvolupen la seva acció durant la nit. Com a solució d'aquest inconvenient, s'han desenvolupat uns aparells electrònics anomenats "detectors d'ultrasò", que aprofiten els crits que emeten els ratpenats com a sistema d'ecolocalització que s'utilitzen per estudiar la vida d'aquests animals. La senyal de freqüència emesa pel quiròpter està situada fora dels límits d'audició de la oïda humana (entre $20 \mathrm{~Hz}$ i $20 \mathrm{kHz}$ ). Són molts els tipus de detectors, amb diferents components i usos a nivell professional o a nivell de camp. Tot i així, existeixen diversos tipus de sistemes utilitzats per a la conversió i tractament dels ultrasons. En aquesta pràctica utilitzarem el 
detector heterodí Bat Tune (figura 1), que sintonitza una freqüència $\mathrm{i}$ segons el soroll audible (generalment entre 20 i $120 \mathrm{kHz}$ ) que emet aquest es pot tenir una aproximació de l'espècie detectada sobre el terreny. Només se sent els crits emesos a freqüències molt properes a la sintonitzada. Generalment, no permeten fer enregistraments dels crits dels detectors i són més econòmics (Arcas P.; Fenollar J, 2018).

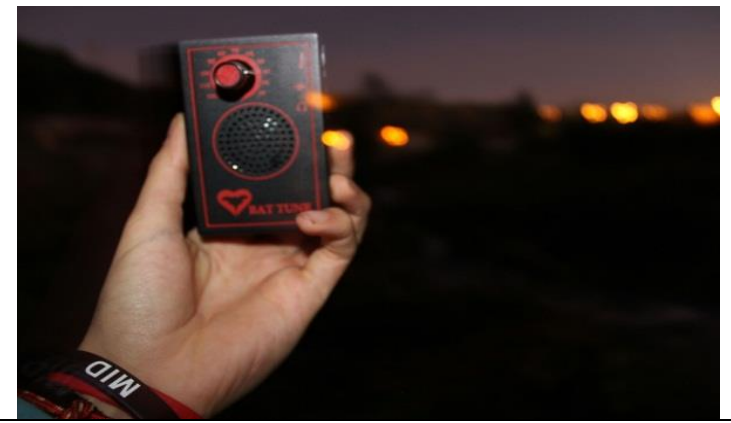

Figura 1. Detector heterodí emprat, Bat Tune.

La millor època per fer sortir a sentir ratpenats és entre maig i octubre. A les nits de juny $\mathrm{i}$ juliol, quan les nits són curtes i càlides, els insectes abunden a tot arreu i els ratpenats inicien la cria anual (Flaquer, i Puig, 2012).

Els ratpenats són més actius a les nits fosques, humides i sense vent. És molt possible que la raó de no sortir en nits de lluna plena sigui per les facilitats que dóna la llum de la lluna per als seus depredadors. No obstant, en nits de lluna plena ens serà més fàcil observar-los visualment, tot i que hi hagin menor nombre d'individus caçant. Els ratpenats toleren la pluja però no suporten les condicions de vent (Flaquer, i Puig, 2012).

\section{FONAMENTS TEÒRICS}

Amb la freqüència d'ultrasò detectada amb el detector Bat Tune es pot calcular els diferents paràmetres físics relacionats amb les ones sonores com: El període $(T)$, la freqüència angular o pulsació $(w)$, la longitud d'ona $(\lambda)$ i el nombre d'ona $(k)$.
A continuació, es realitza una breu explicació dels diferents paràmetres físics ondulatoris (Mercadé, Serra, Armengol, 2009).

1) Freqüència $\boldsymbol{f}$. El nombre d'oscil/lacions completes que fa un punt de l'ona en 1 segon, i, per tant, és la magnitud inversa del període. La seva unitat en el SI és I'hertz $(\mathrm{Hz})$ que equival a $\mathrm{s}-1$.

2) Període T. És el temps que triga un punt de l'ona en fer una oscil-lació completa (pujada-baixadapujada). També es defineix com el temps que triga l'ona en recórrer una distància equivalent a la seva longitud d'ona, $\lambda$. La seva unitat en el SI és el segon $(s)$. $T=1 / f$.

3) Freqüència angular o pulsació $w$. Coincideix amb la velocitat angular, ens indica quina és la velocitat del moviment. La seva unitat en el SI és el radian/segon $(\mathrm{rad} / \mathrm{s}) . w=2 \pi f$.

4) Longitud d'ona $\lambda$ : És la distància entre dos punts d'ona que es troben en el mateix estat de vibració. La seva unitat en el SI és el metre $(m)$. $\lambda=\mathrm{v} / \mathrm{f}$, on $v$ és la velocitat de propagació del so en l'aire de $340 \mathrm{~m} / \mathrm{s}$.

5) Nombre d’ona $\boldsymbol{k}$ : Es pot definir com el nombre de vegades que es repeteix l'ona en una longitud de $2 \pi$ unitats de longitud. La seva unitat en el SI és $\operatorname{radian} / \mathrm{metre}(\mathrm{rad} / \mathrm{m}) . \mathrm{k}=2 \pi / \lambda$.

\section{PROCEDIMENT}

Agafeu el detector i sota un fanal o a un lloc on normalment hi veieu ratpenats volant (bassa d'aigua, un jardí o un camp de fruita), feu pràctiques per tal de reconèixer el so que fan els ratpenats a través de l'aparell. Engegueu el detector enfoqueulo mirant amunt i sintonitzeu a diferents freqüències per tal de identificar el tipus de ratpenat (Flaquer, Puig, 2012).

\section{ANÀLISI DE RESULTATS}

Mitjançant la freqüència $(f)$ d’emissió del ratpenat, es pot determinar el valor dels diferents paràmetres físics ondulatoris, tal com es presenta en la taula 1.

\begin{tabular}{|c|c|c|c|c|c|c|c|}
\hline $\begin{array}{c}\text { Espècie de } \\
\text { ratpenat }\end{array}$ & Nom comú & $\begin{array}{c}\text { Frequè̀ncia } \\
\text { detectada }(\mathrm{kHz}) \\
\text { amb el detector }\end{array}$ & $\begin{array}{c}\text { Freqüència } \\
\text { màxima }(\mathrm{kHz}) \\
\text { del ratpenat }\end{array}$ & $\begin{array}{c}\text { Període } \\
(\mathrm{s})\end{array}$ & $\begin{array}{c}\text { Frequè̀ncia } \\
\text { angular o pulsació } \\
\mathrm{w}(\mathrm{rad} / \mathrm{s})\end{array}$ & $\begin{array}{c}\text { Longitud d'ona } \\
\lambda(\mathrm{m})\end{array}$ & $\begin{array}{c}\text { Nombre d'ona } \\
\mathrm{k}(\mathrm{rad} / \mathrm{m})\end{array}$ \\
\hline & & & & & & \\
\hline
\end{tabular}


A partir d'aquestes taules, es poden comparar els diferents paràmetres calculats segons la freqüència del quiròpter, així com fer gràfiques de les diferents variables calculades segons la freqüència detectada, així com, el nombre de ratpenats detectats segons la seva freqüència.

\section{Exemple d’aplicació:}

Un ratpenat emet polsos d'ultrasons en una gama entre 74 i $85 \mathrm{kHz}$ detectat amb el Bat Tune.

a) Quin és el període (T), la velocitat angular ( $w)$, la longitud d'ona $(\lambda)$ i el nombre d'ona $(k)$ que emet el ratpenat?

b) A quin tipus de ratpenat correspon?

Dada: $v(\mathrm{so})=340 \mathrm{~m} / \mathrm{s}$.

A partir de la Taula 1 podem calcular les diferents paràmetres físics relacionats amb les ones sonores.

- Freqüència: :

$$
\begin{aligned}
& \text { ○ } 74 \mathrm{kHz} * \frac{1000 \mathrm{~Hz}}{1 \mathrm{kHz}}=74000 \mathrm{~Hz} \\
& \text { ○ } 85 \mathrm{kHz} * \frac{1000 \mathrm{~Hz}}{1 \mathrm{kHz}}=85000 \mathrm{~Hz}
\end{aligned}
$$

- Període (T):

$$
\begin{aligned}
\circ T & =\frac{1}{f}=\frac{1}{74000}=1.4^{*} 10^{-5} \mathrm{~S} \\
\circ \quad T & =\frac{1}{f}=\frac{1}{85000}=1.2 * 10^{-5} \mathrm{~S}
\end{aligned}
$$

- La freqüència angular o pulsació $(w)$ :

$$
\begin{aligned}
& \circ \quad w=2 \pi f=2 * \pi^{*} 74000=4.6^{*} 10^{5} \mathrm{rad} / \mathrm{s} \\
& \circ \quad w=2 \pi f=2{ }^{*} \pi^{*} 85000=5.3^{*} 10^{5} \mathrm{rad} / \mathrm{s}
\end{aligned}
$$

- La longitud d'ona $(\lambda)$ :

$$
\begin{aligned}
\circ \lambda & =\frac{v}{f}=\frac{340}{74000}=4.6^{*} 10^{-3} \mathrm{~m} \\
\circ \lambda & =\frac{v}{f}=\frac{340}{85000}=4^{*} 10^{-3} \mathrm{~m}
\end{aligned}
$$

- El nombre d'ona $(k)$ :

$$
\begin{aligned}
& \circ k=\frac{2 \pi}{\lambda}=\frac{2 \pi}{4.6 * 10^{-3}}=1365,9 \mathrm{rad} / \mathrm{m} \\
& \circ k=\frac{2 \pi}{\lambda}=\frac{2 \pi}{5.3 * 10^{-3}}=1185,5 \mathrm{rad} / \mathrm{m}
\end{aligned}
$$

Alhora, si observem la taula de freqüències de la figura 2, el quiròpter que hem detectat és el ratpenat de ferradura gran (Rhinolophus ferrum-equinum).

\section{CONCLUSIONS}

En aquesta pràctica es pretén fomentar el treball col-laboratiu, l'aplicació del mètode científic i interessar i conscienciar a l'alumnat en la conservació dels ratpenats o quiròpters. També, gràcies a aquesta experiència ens permet aplicar les diferents variables estudiades del so en classe. En futurs treballs podrien fer una estudi més extens d' una zona en concret i participar en projectes de seguiment de ratpenats a nivell d'aficionat, com per exemple: QuiroRius [5] i el SEguimiento de QUIròpters amb ultrasons (SEQUI) [6] de la fundació Limne.

\section{Taula de freqüències}

Frequeències característiques dels quiròpters que podem trobar a Catalunya. RINOLÓFIDS

Ratpenat de ferradura gran (Rhinolophus ferrum-equinum) $\quad 79,7 \quad 74-85$ Ratpenat de ferradura mediterrani (Rhinolophus euryale) $\begin{array}{lcc}\text { Ratpenat de ferradura petit (Rhinolophus hipposideros) } & 107,5 & 104-110\end{array}$ VESPERTILIÓNIDS

Ratpenat de cova (Miniopterus schreibersi)

Ratpenat de musell llarg (Myotis myotis)

Ratpenat de musell agut (Myotis blythii)

Ratpenat d'aigua (Myotis daubentonii)

Ratpenat de peus grans (Myotis capaccin

$\begin{array}{cc}53,9 & 50-57,5 \\ 37,1 & 33-41 \\ 53,2 & 42-64 \\ 42,7 & 39-46 \\ 45,1 & 41-49\end{array}$

Figura 2. Taula de freqüències dels ratpenats a Catalunya, disponible a [3].

\section{AGRAIIMENTS}

Agraïm la col-laboració del professor Manel Sánchez.

\section{REFERÈNCIES}

ARCAS P.; FENOLLAR J. (2018). Detecció i identificació de quiròpters segons la seva bioacústica. Publicaciones didácticas. Revista profesional de investigación, docencia y recursos didácticos. 95, 346-362.

CORTÉS-CALVA, P. (2013). Ecolocalización (una visión a los quirópteros). THERYA, 4 (1), 9-14.

FLAQUER, C.; PUIG, X. (2012). Els ratpenats de Catalunya. Figueres: Brau Edicions. ISBN: 97884-96905-79-5.

HERNÁNDEZ V. J.; OLIVER P. (2012). Murciélagos. Introducción a las especies ibéricas. Tundra: Cuadernos de Naturaleza Trunda. ISBN13: 97884-93989-00-2.

MERCADÉ J.; SERRA S.; ARMENGOL M. (2009). Física 2. Batxillerat. Editorial Mc Graw Hill.

\section{Pàgines d'Internet amb informació sobre els ratpenats o quiròpters:}

[1] El manual Bat Tune :

[http://www.quirorius.org/pdf/Manual_Bat_Tune. pdf] 
[2] Fitxes de ratpenats:

http://www.ratpenats.org/CAT/especies/Mmy.ph $\mathrm{p}$

[3] Taula de freqüències. Freqüències característiques dels quiròpters que podem trobar a Catalunya:

http://www.quirorius.org/pdf/Taula_frequencies.pdf

[4] Ratpenats.org: http://www.ratpenats.org/

\section{Projectes de seguiment de quiròpters:}

[5] QuiroRius: seguiment de ratpenats aquàtics: http://www.quirorius.org/el-projecte/

[6] Fundació Limne: SEguimient de QUlròpters amb ultrasons (SEQUI): http://limne.org/index.php/es/?option=com_cont ent\&view=article\&layout=edit\&id $=85$ 